\title{
Direct Oral Anticoagulants, Bleeding Risk in Patients with Atrial Fibrillation, CHADS2 $\geqslant 3$ or HAS-BLED $\geqslant 3$
}

\author{
Acanfora $\mathbf{D}^{1^{*}}$, Casucci $\mathbf{G}^{2}$, Ciccone $\mathbf{M C}^{3}$, Scicchitano $\mathbf{P}^{3}$, Montefusco $\mathbf{G}^{1}$, Lanzillo $\mathrm{A}^{1}$, Acanfora $\mathrm{C}^{1}$ and Lanzillo $\mathbf{B}^{1}$ \\ ${ }^{1}$ Institute of Care and Scientific Research, Rehabilitation Institute of Telese Terme, Benevento, Italy \\ ${ }^{2}$ San Francesco Hospital-TeleseTerme (BN), Italy \\ ${ }^{3}$ Department of Emergency and Organ Transplantation, Section of Cardiovascular Diseases, University of Bari, School of Medicine, Bari, Italy
}

\begin{abstract}
To evaluated the safety of direct oral anticoagulants as compared to warfarin in a subgroup of patients with atrial fibrillation (AF) who should undergo antithrombotic therapy such as patients with $\mathrm{CHADS}_{2}$ score $\geq 3$. We evaluated the incidence of major bleeding in patients with $A F$ and CHADS $_{2}$ score $\geq 3$ in the RE-LY, ROCKET-AF, ARISTOTLE, and ENGAGE studies. Also we evaluated the incidence of major bleeding in patients at higher hemorrhagic risk (HAS-BLED $\geq 3$ ). Data was derived from eleven studies whose results came from the pivotal trials. Our aim was to propose a critical debate on the collected data.

There were some striking differences between the 4 considered studies: a high percentage of bleeding in the subpopulation at high risk of stroke or systemic embolism or at high risk of bleeding. Some studies reported a higher frequency of bleeding in the warfarin arm. The excess in the bleeding rate in the warfarin group was likely to be associated with Asian ethnicity as Asian patients often have higher warfarin sensitivity. Asian patients may require lower initiation and maintenance doses of warfarin. Careful evaluation of patients in need for anticoagulation is essential for the prescription of these drugs and the extension of global use.
\end{abstract}

Keywords: Atrial fibrillation; Warfarin; Direct oral anticoagulants; Bleeding

\section{Key Points}

- Few data exist regarding the use of NOACs in patients with high risk of stroke, systemic embolism and bleeding $\left(\mathrm{CHADS}_{2} \geq 3\right.$; HAS-BLED $\geq 3$ ).

- The indirect comparison meta-analysis between NOACs represents hypothesis generators and they cannot provide definitive answers.

- We proposed a critical debate on the data collected from the NOACs in the pivotal trials.

\section{Introduction}

Atrial fibrillation (AF) is a condition associated with a high risk of stroke and systemic embolism. Prevention of these complications was carried out with long-term anticoagulant therapy. Until a few years ago the therapeutic standard was dose-adjusted vitamin $\mathrm{K}$ antagonist (VKA); recently, oral anticoagulant therapy has been extended with the use of four new non-VKA antagonist drugs (NOACs) (Dabigatran, Rivaroxaban, Apixaban and Edoxaban). They were approved following the detection in 4 dose-adjusted phase III, warfarin controlled, randomized controlled trials (RCTs) [1-4].

All of the trials showed NOACs efficacy in preventing stroke or systemic embolism similarly or better than warfarin; in addition, they dimmed a safety profile higher or similar to warfarin.

Some differences among the studies must be considered. Firstly, the mechanism of action of the anticoagulants diverges from each other; dabigatran is a direct thrombin inhibitor whereas rivaroxaban, apixaban and edoxaban are direct factor Xa inhibitors. Three of the four studies used a double-dummy double-blind design. The RE-LY study used a blinded strategy for the two doses of dabigatran, but an open-label evaluation for warfarin versus dabigatran.
Given a similar efficacy and safety profile for the four NOACs compared to warfarin, the differences in the enrolled populations must be considered such as higher risk of stroke-systemic embolism ( $\mathrm{CHADS}_{2}$ score) [5] or bleeding (HAS-BLED score) [6]. The percentage of patients with $\mathrm{CHADS}_{2} \geq 3$ in the four trials was, respectively: $32 \%$ in the RE-LY study, $87 \%$ in the ROCKET-AF study, $30 \%$ in the ARISTOTLE study and 53\% in the ENGAGE study; meanwhile, the percentage of patients with HAS-BLED $\geq 3$ was: $10 \%$ in the RE-LY, $62 \%$ in the ROCKET-AF, $23 \%$ in the ARISTOTLE and $46 \%$ in the ENGAGE.

Although the four studies have broadly defined bleeding according to the criteria of the International Society on Thrombosis and Haemostasis (ISTH), some have made changes that may have had an impact on the results.

The ARISTOTLE study specified a 24-hour time window for the $\geq 2$ $\mathrm{g} / \mathrm{dL}$ reduction of hemoglobin, while the other 3 studies did not specify a time limit. In the same study it was specified that the transfusion of $\geq$ 2 units of concentrated red blood cells was a major bleeding criterion but without adding whole blood. The other three phase III studies considered the transfusion of $\geq 2$ units of concentrated red blood cells or whole blood (Table 1).

*Corresponding author: Domenico Acanfora, Maugeri Scientific Clinical Institutes SpA SB, Institute of Care and Scientific Research, Rehabilitation Institute of Telese Terme, Via Bagni Vecchi 1, 82037 Telese Terme (BN), Italy, Tel: +393382326970; Fax: +39824909614; E-mail: domenico.acanfora@icsmaugeri.it

Received April 27, 2018; Accepted May 17, 2018; Published May 24, 2018

Citation: Acanfora D, Casucci G, Ciccone MC, Scicchitano P, Montefusco G, et al (2018) Direct Oral Anticoagulants, Bleeding Risk in Patients with Atrial Fibrillation, CHADS2 $\geq 3$ or HAS-BLED $\geq 3$. Cardiovasc Pharm Open Access 7: 240. doi 10.4172/2329-6607.1000240

Copyright: (c) 2018 Acanfora D, et al. This is an open-access article distributed under the terms of the Creative Commons Attribution License, which permits unrestricted use, distribution, and reproduction in any medium, provided the original author and source are credited. 


\begin{tabular}{|c|l|}
\hline RE-LY & $\begin{array}{l}\text { Reduction in the } \mathrm{Hb} \text { level of } \geq 2 \mathrm{~g} / \mathrm{dL}, \text { transfusion of } \geq 2 \text { units of blood or packed red cells, or symptomatic bleeding in a critical area or } \\
\text { organ, or bleeding that leads to death. }\end{array}$ \\
\hline ROCKET-AF ${ }^{2}$ & $\begin{array}{l}\text { Clinically overt bleeding associated with any of the following: fatal outcome, involvement of a critical anatomic site, fall in Hb concentration } \geq \\
2 \mathrm{~g} / \mathrm{dL} \text {, transfusion of } \geq 2 \text { units of whole blood or packed red blood cells, or permanent disability }\end{array}$ \\
\hline ARISTOTLE ${ }^{3}$ & $\begin{array}{l}\text { ISTH: Clinically overt bleeding accompanied by a decrease in the } \mathrm{Hb} \text { level of } \geq 2 \mathrm{~g} / \mathrm{dL} \text { over } 24 \mathrm{~h} \text { or transfusion of } \geq 2 \mathrm{units} \text { of packed red } \\
\text { cells, occurring at a critical site, or resulting in death }\end{array}$ \\
\hline ENGAGE AF ${ }^{4}$ & $\begin{array}{l}\text { ISTH with minor modifications for } \mathrm{Hb} \text { decrease and blood transfusion requirements. Clinically overt bleeding event that met } \geq 1 \text { of the } \\
\text { following: fatal bleeding, symptomatic bleeding in a critical site, clinically overt bleeding event that causes a fall in } \mathrm{Hb} \text { level of } \geq 2.0 \mathrm{~g} / \mathrm{dL}, \\
\text { adjusted for transfusions. Each unit of packed red blood cell or whole blood is counted as a } 1.0 \mathrm{~g} / \mathrm{dL} \mathrm{decrease} \mathrm{in} \mathrm{Hb}\end{array}$ \\
\hline
\end{tabular}

$\mathrm{HB}=$ Haemoglobin; ISTH= International Society on Thrombosis and Haemostasis

Table 1: Definition of major bleeding in the four pivotal trials.

The aim of this review is to evaluate the safety of direct oral anticoagulants as compared to warfarin in a subgroup of patients with AF that was mandatory antithrombotic therapy such as patients with $\mathrm{CHADS}_{2} \geq 3$.

We evaluated the incidence of major bleeding in a patients with $\mathrm{AF}$ and $\mathrm{CHADS}_{2} \geq 3$ in the RE-LY, ROCKET-AF, ARISTOTLE, and ENGAGE studies. Also we evaluated the incidence of major bleeding in patients at higher hemorrhagic risk (HAS-BLED $\geq 3$ ).

\section{Methods}

We searched MEDLINE, Cochrane Central Register of Controlled Trials, metaregister of Controlled Trial, ClinicalTrial.gov and PubMed in February 2018 for all phase III randomized controlled trial of patients receiving dabigatran, rivaroxaban, apixaban or edoxaban versus warfarin for the prevention of trombotic events in AF. Keywords were "atrial fibrillation", "warfarin", "oral thrombin inhibitor", "oral factor Xa inhibitor", "dabigatran", "rivaroxaban”, "apixaban”, "edoxaban”, "CHADS" and "HAS-BLED". Data was derived from eleven studies who reported data of the pivotal trials [1-4,7-14] (Figure 1).

\section{Statistical analysis}

We did not conduct any statistical analyses because, in our opinion, the indirect comparison meta-analysis between NOACs represents hypothesis generators and cannot provide definitive answers.

\section{Main Results}

We included 33.117 patients with $\mathrm{AF}$ and $\mathrm{CHADS}_{2} \geq 3$ and 22.405 patients with $\mathrm{AF}$ and HAS-BLED $\geq 3$ enrolled in the 4 randomized trials, comparing the incidence of major bleeding of dabigatran (110 $\mathrm{mg}$ and $150 \mathrm{mg}$ ) BID, rivaroxaban $20 \mathrm{mg}$ QD, apixaban $5 \mathrm{mg}$ BID and edoxabanhigh dose (60 mg-30 mg) QD with warfarin.

Table 2 summarizes the results of our observation. The percentage of patients with $\mathrm{CHADS}_{2} \geq 3$ ranged $15.1 \%$ to $43.5 \%$. The highest frequency of $\mathrm{CHADS}_{2} \geq 3$ was in the group of patients treated with rivaroxaban $(43.5 \%)$. In these patients with a high thromboembolic risk there were a number of major bleeds similar to those recorded in the ARISTOTLE study for apixaban, even if the percentage of bleedings in the warfarin group is higher. In the RE-LY study, the frequency of major bleeding is approximately twice that of rivaroxaban and apixaban in the dabigatran $110 \mathrm{mg}$ group, dabigtran $150 \mathrm{mg}$ and warfarin. Bleeding data for the ENGAGE study stratified for $\mathrm{CHADS}_{2}$ $\geq 3$ is not available.

A high proportion of patients with a high risk of bleeding was present in the ROCKET-AF study (Rivaroxaban 30.7\%, Warfarin $31.2 \%$ ), while it was poorly represented in the RE-LY and ARISTOTLE studies. In the ENGAGE study, about $25 \%$ of patients in the both edoxaban and warfarin arms had a HAS-BLED $\geq 3$ (Table 3).

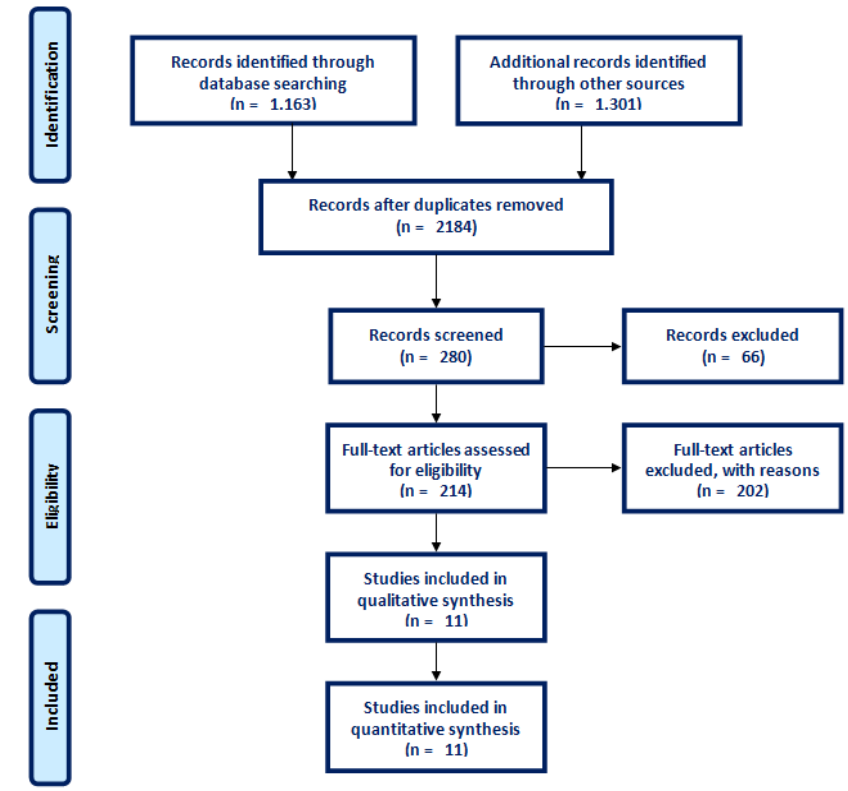

Figure 1: Flow diagram of the searched trials

A higher number of major bleedings, in patients with HAS-BLED $\geq 3$, occurred in the RE-LY study in the dabigatran $110 \mathrm{mg}$ arm, dabigatran $150 \mathrm{mg}$ and warfarin. Therefore, a lower rate of major bleeding was registered in patients at higher risk for bleeding while on therapy with edoxaban and rivaroxaban.

The lowest percentage of major bleedings in the ENGAGE study in patients with HAS-BLED $\geq 3$ is not exclusively due to the different definition of bleeding but it is plausible to derive from the migration from the higher to the lower dose. In fact, the proportion of patients in the warfarin group is similar to that recorded for rivaroxaban.

\section{Discussion}

Anticoagulant therapy is a milestone for the prevention of thromboembolic events in patients with atrial fibrillation. Studies showed the efficacy of warfarin in reducing thromboembolic stroke in patients with atrial fibrillation. Recently, the introduction of NOACs has helped to reduce stroke frequency in these patients by a further $16 \%[1-4]$.

The efficacy and safety of anticoagulant therapy are primarily guided by adherence to treatment and the characteristics of the patients. The main objective in patients treated with warfarin is to maintain INR in the therapeutic range (TTR $>70 \%)$. It is possible to select patients with an appropriate TTR by applying the SAMe-TT $\mathrm{R}_{2}$ score. Patients with $\mathrm{SAMe}^{-\mathrm{TT}_{2}} \mathrm{R}_{2} \geq 2$ should treat them with NOACs [15]. The choice 


\begin{tabular}{|c|c|c|c|c|c|c|}
\hline \multirow{2}{*}{\multicolumn{2}{|c|}{ RCTs Patients }} & \multicolumn{3}{|c|}{ CHADS $_{2} \geq 3$} & \multicolumn{2}{|c|}{ Major Bleeding } \\
\hline & & NOAC & Warfarin & Total & NOAC & Warfarin \\
\hline $\begin{array}{c}\text { Dabigatran } 110 \mathrm{mg}(\mathrm{N} / \%) \\
\text { PTs\% / y }\end{array}$ & 12037 & 1951 (16.2) & $1914(15.9)$ & 3865 (32.1) & $\begin{array}{c}147(7.5) \\
3.75\end{array}$ & $\begin{array}{c}172(9.0) \\
4.5\end{array}$ \\
\hline $\begin{array}{c}\text { Dabigatran } 150 \mathrm{mg} \mathrm{(N/ \% )} \\
\text { PTs } \% / y\end{array}$ & 12098 & 1965 (16.2) & $1914(15.8)$ & $3879(32.1)$ & $\begin{array}{c}188(9.6) \\
4.8\end{array}$ & $\begin{array}{c}172(9.0) \\
4.5\end{array}$ \\
\hline $\begin{array}{c}\text { Rivaroxaban (N/\%) } \\
\text { Pts\% / y }\end{array}$ & 14264 & 6205 (43.5) & $6197(43.4)$ & $12402(86.9)$ & $\begin{array}{l}337(5.4) \\
2.84\end{array}$ & $\begin{array}{c}337(5.4) \\
2.84\end{array}$ \\
\hline $\begin{array}{c}\text { Apixaban (N/\%) } \\
\text { PTs } \% / y\end{array}$ & 18201 & $2758(15.2)$ & $2744(15.1)$ & $5502(30.2)$ & $\begin{array}{c}143(5.2) \\
2.88\end{array}$ & $\begin{array}{c}188(6.9) \\
3.83\end{array}$ \\
\hline Edoxaban HD (N/\%) & 14071 & 3784 (26.3) & 3685 (26.2) & 7469 (53.1) & $\mathrm{N} / \mathrm{A}$ & $\mathrm{N} / \mathrm{A}$ \\
\hline
\end{tabular}

$\mathrm{CHADS}_{2}=$ (congestive heart failure, hypertension, age $\geq 75$ years, diabetes mellitus, stroke [double weight]); RCTs= randomized controlled trials; NOAC= non-VKA antagonist drugs; $\mathrm{N}=$ Number; Pts=Patients; $\mathrm{HD}=$ Higher-dose.

Table 2: Major bleeding in patients with $\mathrm{CHADS}_{2} \geq 3$ in the four pivotal trials.

\begin{tabular}{|c|c|c|c|c|c|c|}
\hline \multirow{2}{*}{\multicolumn{2}{|c|}{ RCTs Patients }} & \multicolumn{3}{|c|}{ HAS-BLED $\geq 3$} & \multicolumn{2}{|c|}{ Major Bleeding } \\
\hline & & NOAC & Warfarin & Total & NOAC & Warfarin \\
\hline $\begin{array}{c}\text { Dabigatran } 110 \text { mg N (\%) } \\
\text { Pts\% / y }\end{array}$ & 18113 & $1119(6.2)$ & $1163(6.4)$ & $2282(37.9)$ & $\begin{array}{c}103(9.2) \\
4.6\end{array}$ & $\begin{array}{c}119(10.2) \\
5.1\end{array}$ \\
\hline $\begin{array}{c}\text { Dabigatran } 150 \text { mg N (\%) } \\
\text { Pts\% / y }\end{array}$ & 18113 & $1147(6.3)$ & $1163(6.4)$ & $2310(12.7)$ & $\begin{array}{c}137(11.9) \\
5.95\end{array}$ & $\begin{array}{c}119(10.2) \\
5.1\end{array}$ \\
\hline $\begin{array}{c}\text { Rivaroxaban N (\%) } \\
\text { Pts\% / y }\end{array}$ & 14264 & $4373(30.7)$ & 4464 (31.2) & 8837 (61.9) & $\begin{array}{l}265(6.0) \\
3.15\end{array}$ & $\begin{array}{c}266(6.0) \\
3.15\end{array}$ \\
\hline $\begin{array}{c}\text { Apixaban N (\%) } \\
\text { Pts\% / y }\end{array}$ & 18201 & 2097 (11.5) & 2067 (11.4) & 4164 (22.9) & $\begin{array}{c}129(6.15) \\
3.41\end{array}$ & $\begin{array}{c}154(7.5) \\
4.16\end{array}$ \\
\hline $\begin{array}{c}\text { Edoxaban (HD)* N (\%) } \\
P t s \% / y\end{array}$ & 9387 & 2397 (25.5) & 2415 (25.7) & $4812(51.2)$ & $\begin{array}{c}110(4.6) \\
1.68\end{array}$ & $\begin{array}{c}145(6.0) \\
2.14\end{array}$ \\
\hline
\end{tabular}

HAS-BLED= (Hypertension, Abnormal renal/liver function, Stroke, Bleeding history or predisposition, Labile international normalized ratio, Elderly (>65 years), Drugs/ alcohol concomitantly); RCTs= randomized controlled trials; NOAC= non-VKA antagonist drugs; N=Number; Pts=Patients; HD=Higher-dose; ${ }^{*} \mathrm{Patients} \mathrm{excluded} \mathrm{if} \mathrm{Creatine}$ Clearance $(\mathrm{CrCl}) \geq 95 \mathrm{ml} / \mathrm{min}$ (The US Food and Drug Administration approved the higher-dose regimen for patients with $\mathrm{CrCl} 15-95 \mathrm{~mL} / \mathrm{min}$ ).

Table 3: Major bleeding in patients with HAS-BLED $\geq 3$ in the four pivotal trials.

among all of the direct oral anticoagulant to use is related to the data derived from the available RCTs. Unfortunately we must note that there are differences between the various studies.

Methodological differences (study design), patient populations, and definition of outcomes clearly exist across the four phase III RCTs of NOACs for stroke prevention in patients with AF. It is not possible to modify or standardize the study design or the definition of the outcomes of the registration trials. Therefore, we extrapolate patients from the RCTs at high thromboembolic risk or major bleedings in order to find information about this peculiar subpopulation of patients. At the best of our knowledge, this is the first report analyzing the risk of major bleeding in patients with $\mathrm{CHADS}_{2} \geq 3$ and HAS-BLED $\geq 3$.

Our observation in patients at higher risk of stroke or systemic embolism and at higher risk of bleeding shows substantial differences compared to the results of the registered trials. Great differences exist in the population enrolled in the four studies in terms of thromboembolic risk $\left(\mathrm{CHADS}_{2} \geq 3\right)$. The highest rate of patients with $\mathrm{CHADS}_{2} \geq 3$ is in ROCKET-AF (87\%) and ENGAGE (52\%). In the ARISTOTLE study (30\%) and RE-LY study (32\%), only one third of the patients enrolled had $\mathrm{CHADS}_{2} \geq 3$; one third had $\mathrm{CHADS}_{2} \leq 1$, and therefore a controversial indication to anticoagulant treatment. Extrapolating the patients with $\mathrm{CHADS}_{2} \geq 3$ it is possible to obtain information not directly deducible from the RCTs.

In patients with $\mathrm{CHADS}_{2} \geq 3$ the incidence of major bleeding is similar in patients treated with rivaroxaban or warfarin, whereas for patients enrolled in RE-LY the incidence of major bleeding is high for both dabigatran $110 \mathrm{mg}$, dabigatran $150 \mathrm{mg}$ and warfarin. This different incidence of major bleeding appears to be independent of the dose used but linked to the patient's risk profile. Factors that may influence pharmacokinetics and pharmacodynamics such as comorbidity, advanced age, heart failure, hepatic or renal insufficiency increase the risk of bleeding. This could explain the excess of major bleeding even in patients treated with warfarin, and contribute to lower time in the therapeutic range.

It is not possible to extrapolate data on major bleeds from the ENGAGE study because the incidence of these events stratified by $\mathrm{CHADS}_{2} \geq 3$ is not available. CHA DS VASc score was used in this study. A significant reduction in major bleeding in the ARISTOTLE study (Apixaban $4.07 \% /$ yrvs Warfarin $6.01 \%$ yr) and the ENGAGE study (Edoxaban 2.75\%/ yrvs, Warfarin 3.43\%/ yr) are to be reported. Nevertheless, the data from ARISTOTLE showed an excess in bleeding rate in the warfarin group likely to be associated with a large number of Asian patients (16\%) who have higher warfarin sensitivity. Asian patients may require lower initiation and maintenance doses of warfarin. Single nucleotide polymorphisms in the CYP2C9 and VKORC1 genes have been associated with variable warfarin dose requirements. In the ENGAGE study, the length of follow-up and dose reduction throughout the study period is the most plausible explanation.

Our results show that rivaroxaban has the lowest incidence of major bleeding if the patients of the four phase III RCTs of NOACs are stratified by HAS-BLED $\geq 3$. As the NOACs RCTs had heterogeneity in the populations recruited, we concluded that homogenizing for thromboembolic and bleeding risk allows the rivaroxaban to show a better safety profile. The clinical safety data derived from the RCTs of NOACs are not automatically comparable and consequently it may not be correct to express comparative judgments between different NOACs. A consensus document attempted to propose some guiding criteria in clinical practice $[16,17]$, but it should be stressed that these 
are evaluations not-supported by randomized comparative studies. However, it is necessary to know in detail the NOACs and the results of the RCTs studies in order to adapt the optimal antithrombotic therapy for each patient's characteristics based on the action mechanism, the pharmacokinetics and pharmacodynamics of the NOACs, the patient's thromboembolic and hemorrhagic risk profile, the presence of comorbidity, and, finally, the ethnicity of the individuals.

Our analysis calls for reflection and the opening of a debate on the choice of NAOCs in patients with AF. The correct choice of NOACs has significant clinical implications as it is possible to drastically reduce the onset of serious complications such as major bleeding.

\section{Conclusion}

In patients with $\mathrm{AF}$ for whom anticoagulant therapy is mandatory, some observations are necessary for the choice of the drug and the dose to be used to globally transfer the use of NOACs.

\section{Authors' Note}

Domenico Acanfora, Gerardo Casucci, Marco MatteoCiccone, Pietro Scicchitano, Giulio Montefusco, Anna Lanzillo, Chiara Acanfora, Bernardo Lanzillo conceived and designed the study, analyzed and interpreted the data, drafted the article and critically reviewed is intellectual content, and finally approved the version to be submitted for publication.

\section{References}

1. Connolly SJ, Ezekowitz MD, Yusuf S (2009) Dabigatran versus warfarin in patients with atrial fibrillation. N Engl J Med 361: 1139-1151.

2. Patel MR, Mahaffey KW, Garg J (2011) Rivaroxaban versus warfarin in nonvalvular atrial fibrillation. $\mathrm{N}$ Engl J Med 365: 883-891.

3. Granger CB, Alexander JH, McMurray JJV (2011) Apixaban versus warfarin in patients with atrial fibrillation. N Engl J Med 365: 981-992.

4. Giugliano RP, Ruff CT, Brounwald E (2013) Edoxaban versus warfarin in patients with atrial fibrillation. N Engl J Med 369: 2093-2104.
5. Gage BF, Waterman AD, Shannon W (2001) Validation of clinical classification schemes for predicting stroke: results from the National Registry of Atria Fibrillation. JAMA 285: 2864-2870.

6. Roldán V, Marín F, Manzano-Fernández S (2013) The HAS-BLED score has better prediction accuracy for major bleeding than CHADS2 or CHA2DS2-VASc scores in anticoagulated patients with atrial fibrillation. JACC 62: 2199-2204.

7. Pisters R, Lane DA, Nieuwlaat R (2010) A novel user-friendly score (HAS BLED) to asses 1-year risk of major bleeding in patients with atrial fibrillation: the Euro Heart Survey. CHEST 138: 1093-1100.

8. Jonathan PP, Jyotsna G, Manesh RP (2014) Management of major bleeding events in patients treated with rivaroxaban vs. warfarin: results from the ROCKET AF trial. EHJ 35: 1873-1880.

9. Claes $\mathrm{H}$, Elaine $\mathrm{MH}$, John HA (2015) Clinical outcomes and management associated with major bleeding in patients with atrial fibrillation treated with apixaban or warfarin: insights from the ARISTOTLE trial. EHJ 36: 1264-1272.

10. Flaker G, Renato DL, Hylek E (2014) Amiodarone, anticoagulation and clinical events in patients with atrial fibrillation. Insights from the ARISTOTLE Trial. JACC 64: 1541-1550.

11. Proietti M, Hijazi Z, Andersson U (2018) Comparison of bleeding risk scores in patients with atrial fibrillation: insights from the RE-LY trial. J Intern Med 283: 282-292.

12. Shaun GG, Daniel MW, Jonathan PP (2014) Factors Associated With Major Bleeding Events Insights From the ROCKET AF Trial. J am CollCardiol 63 891-900.

13. De Caterina R, Andersson U, Alexander J (2016) History of bleeding and outcomes with apixaban versus warfarin in patients with atrial fibrillation in the Apixaban for Reduction in Stroke and Other Thromboembolic Events in Atrial Fibrillation trial. Am Heart J 175: 175-183.

14. Kato ET, Giugliano RP, Ruff T (2016) Efficacy and safety of edoxaban in elderly patients with atrial fibrillation in the ENGAGE AF-TIMI 48 trial. JAHA 5: 1-9.

15. Lip GYH, Fauchier L (2016) Atrial fibrillation. Nature Reviews Disease Primers 2: 1-26.

16. Diener HC, Aisenberg J (2016) Choosing a particular oral anticoagulant and dose for stroke prevention in individual patients with non-valvular atrial fibrillation: part 1. Eur Heart J 38: 852-859.

17. Diener HC, Aisenberg J (2016) Choosing a particular oral anticoagulant and dose for stroke prevention in individual patients with non-valvular atrial fibrillation: part 2. Eur Heart J 38: 860-868. 